\title{
CASE STUDY: BYOD IN THE HIGHER EDUCATION CLASSROOM: DISTRACTION OR DISRUPTION? THE ADOPTION OF SPANGLER'S 2016 DIGITAL HUMAN IT INTEGRATION CHARTING SYSTEM
}

\author{
Scott C.Spangler, D.Sc.,Middle Georgia State University, scott.spangler@mga.edu \\ Anthony Rodi, D.Sc.,University of Pittsburgh, afrodi@katz.pitt.edu \\ Misty Kiernan, Middle Georgia State University, misty.kiernan@mga.edu
}

\begin{abstract}
Keywords: Digital Natives, Mobile Learning; BYOD, M-Learning, E-Learning, Higher Education, Creative Pedagogies
\end{abstract}

\begin{abstract}
Digital natives have long been observed as sophisticated individuals with natural abilities to navigate human computer innovations. Original namesakes prescribe the now 26-year-old-original digital generation as one engaged, embraced, immersed and enamored with technology. Coiners of the Millennials and Digital natives, Tapscott and Prensky proclaimed the then youth as a culture of emersion at birthright (Prensky, 2001; Tapscott, 1999). They are and were the Net Generation-individuals obsessed with innovations. Today (2016), the youth culture has not changed: obsession with new innovations, believed to be clairvoyant with technology, and coiners of applications. Only a few dissenting researchers have struck out at the fantasy behind the digital native's sophistications. Starting with Nicholas Carr, and transcending to Bauerlein's "ignorant" rant against the scholarly proclamation machine, other scholars have led the charge to uncover truths and raise concerns over today's mobile generation cleverness. As an example, at the IACIS 2015 conference in Clearwater, Florida, and 2015 EQRC Conference Las Vegas, Nevada, research was presented that explored the Digital Native behaviors and habits of students. Both research explorations uncovered ethnographic evidence of ignorance and addiction issues. In tune, the researchers left a gap in the literature for review. This body of research will seek to uncover and fill in the literature's gap about how digital natives regard mobile computing technologies.
\end{abstract}

Using the previous research and current literature, this paper seeks to understand how digital natives regard the value of their own mobile devices in the Higher Educational environment. Secondly, the research will attempt to answer questions about the 2016 digital native's technology sophistication and use methodologies in higher education domains. But most importantly, this research paper will launch a new six-stage-charting system for understanding technology users and adopters called the Spangler's 2016 Digital Human IT Integration Charting System Model.

\section{INTRODUCTION}

In the late 1800's the newspaper editorials in Southwestern, Pennsylvania were reporting on innovations and ramped growth in technologies: steel manufacturing, radio-wave transmission, and photographic abilities. Additionally, one paper, the Monessen Messenger described a society in decay. The newspaper's editorialists describe an awkward situation whereby youth had taken over in public facilities in an unsightly manner and been bewitched with a new innovation. The innovation was mass produced books being checked out of the Monessen free public library. The editorial's described the youth's innovation bewitching as the fall of society. Today (2016), innovations are again supposedly bewitching youth and causing decay in society. Today's debates about innovations are more about the positive externalities or waves brought into society: depletion of the literacy gap from inexpensive mobile technologies, health and society benefits from the proliferation of information and social justice.

Digital natives today have stricken injustice and society through change and mobile technologies. As an example, digital natives led the charge to strike out various leaderships who create injustice and hardship on nations. 


\section{Issues in Information Systems}

Volume 17, Issue III, pp. 100-108, 2016

Mobile technologies have played a key role from civil uprisings to protests in Saudi Arabia for women's rights to drive and vote; along with Constitutionality reforms in Morocco and Jordan. Nevertheless of the civil actions, the digital native mobile bloggers sought great justice and reform when their peers came under police scrutiny or strikes. The infamous Tahrir Square demonstration in January of 2008, was constructed and led through a sustained mobile application platform on Facebook. The cyber social revolution mobilized college students to strike against state-run factories in the textile market space with inhumane working conditions. Although this strike was a powerful and first ever cyber organized digital youth strike in the Arab and Egyptian world, nothing had further reach than the brutal police state beating death of Khaled Mohamed Saeed (Goodman, 2016; Schmidt, 2013).

Today (2016), mobile technologies have become a beacon for social change, education, and global reach, while providing anytime, anywhere availability for Digital Natives. Fall out from this mobile innovation insurrection have yet to be witnessed.

Digital Natives use mobile devices for everything from communication, to enabling social and political movements, to learning. The mobile space has become the norm for Digital Natives. Classrooms have been transformed to mobile environments with each student possessing multiple devices. This paper seeks to understand how digital natives regard the value of their own mobile devices in the Higher Educational environment.

\section{LITERATURE REVIEW}

Mobile technologies have created convenience, connectivity, and instant knowledge. Traditional Higher Education classrooms are rapidly being transformed from venues of large tacit knowledge transfer to digital natives accessing their own devices for instant learning. The digital native culture is known as the generation who are born into technology, with advanced knowledge and engagement with mobile devices and technologies not known to previous generations (Hull, 2011, p. 194). Although in recent research conducted, scholars have gained a contrasting option about the digital native's abilities and knowledge about innovations especially mobile technology. Some scholars have ethnographically observed a disconnect with digital natives' abilities understanding technology and how it functions (Bauerlein, 2011; Boyd, 2014; Rodi, Spangler, Delorenzo, \& Kohun, 2014; Spangler, 2015).

However the disconnect has been conceived the proliferation of user-friendly human computer inactive devices has charged a digital nation with information. The proliferation of mobile innovations and fingertip ease learning applications may be a generational difference in understanding when comparing findings of Spangler, Boyd, and Bauerlein's research contrasts. Interestingly, formidable scholars forecasted the digital nation of ignorance and stupidity. Carr (2011) cited a culture of gnats and society in destructive behaviors. Conversely, the researcher describes society in a state "wayfaring" dependency upon Google's prolific mobile innovations (Carr, 2015, pp. 132-133).

\section{Higher Education}

In many classrooms, the transfer of knowledge is created between devices. Using previous research from Spangler, Rodi, DeLorenzo and Kohun, 2015, and through current literature, this paper seeks to understand how digital natives regard the value of their own mobile devices in the Higher Educational environment and answer questions about the digital native's technology sophistication and their use of technology in higher education domains.

Recent studies (Spangler, 2015; Rodi, et al., 2014) found similar recognitions in digital natives having shortcomings with software knowledge and sophistications. Specifically both found the digital native culture lacking in software, hardware, and overall knowledge about sophisticated computer programs and programming. This comparatively contrasted past literature that trumpeted cultural successes in technology success (Hart, Gray, Chinburg, Saffarian, \& Hart, 2011; Howe \& Strauss, 2007; Jukes, McCain, Crockett, \& 21st Century Fluency Project, 2010; Palfrey \& Gasser, 2010; E. E. Smith, 2012; J. Smith, Skrbis, \& Western, 2013; Tapscott, 2009, 2010; Zukowski, 2010). Rodi, Spangler, Delorenzo, \& Kohun (2014) captured significant negative attributes of the culture through qualitative interviews. Their research captured negativity in the culture's inability to demonstrate knowledge or usage of basic productivity software and library science research tools. These findings and the furthering research thoughts and 
suggestions from Rodi et al. (2014) grounded this study's questions on understanding technology knowledge, and it's controlling aspects in the current digital native higher education culture.

\section{THE MOTIVATION TO FURTHER INQUIRY}

The original 2015 research from Spangler on digital native students in higher education observed the culture communicating through technology, was based on ethnographic observation and five independent focus groups during a yearlong study at a Mid-Atlantic university, nearly 400 undergraduate students were observed in classrooms and in social domains to determine cultural traits of mobile technology usage.

This research offered deep insights to the habits and engagement of mobile technologies in the academic environments, promoting further research into mobile technologies specifically used in the classroom.

The accompanying 2014 research from Rodi, Spangler, DeLorenzo and Kohun further prompt investigation of the engagement of mobile technologies in the classroom.

Students now use mobile devices for everything from social interaction to classroom engagement with their professors and assignments (Petocz et al., 2013). As a result, educators are adopting the use of mobile devices in their classrooms and they believe that these devices develop communication with students while they motivate, and engage them in online research, submitting online assignments, online discussions and collaboration, and completing online learning activities. The ongoing issue that still exists is trying to balance effective pedagogical approaches with "device distractibility" and the digital divide (Purcell, Heaps, Buchanan, \& Friedrich, 2013).

This finding was also uncovered though Spangler's dissertation. The researcher observed faculty utilizing nontraditional communication and teaching instruments in the classrooms. One faculty member at California University of Pennsylvania created lesson plans for students using GoAnimate.com characterizations. The characterization lesson plans forced students-who couldn't utilize the technology-to gain application insight. Additional, application infusions placed students in gaming's situations whereby they were forced to learn how to use their mobile devices to capture QR codes to gain access into lessons. Again, ethnographic observations uncovered a culture of inadequate knowledge. Students, whom the QR code innovations were originally created for out of false knowledge and need, failed repeatedly to capture the information and needed specialized instructions about downloading applications to mobile devices and formidable knowledge about what to accomplish next. The faculty member, who was astounded by the digital natives "stupidity," was forced to reconcile the innovative teaching methodologies.

\section{BYOD Adoption in the Classroom}

Educators are embracing the BYOD trend and understanding that mobile devices are not only a cultural symbol of Millennials but as a necessity to daily life. In classes where BYOD is encouraged, student bring their own devices such as smartphone, tablets, IPADS and laptops to expand on their personal knowledge and as a result are more active and engaged in classroom participation (Johns, Kyoho, 2015). "The most important m-learning benefit is autonomy, as it supports the success of the other benefits; with autonomy the student is able to take advantage of the anywhere, anytime, when needed, convenience of personalized learning. The best student autonomy comes from good instructional design that offers clear self-guided access to the learning content on a variety of devices" (Khristen, et al, 2014).

Communicating via technology provides more confidence to many students who normally do not participate in traditional classroom interactions due to anxiety, cultural norms or social intimidation. This is especially true with international students who normally do not speak out in class.

Rodi, Spangler, Delorenzo \& Kohun (2014) indicates that the preferred form of engagement is in digital format. The student participants described their preferences over traditional engagement in the form of digital books, digital content and communication via their own devices. In addition, Brumberger (2011) discovered that Digital 
Natives/Millenials prefer visual communication due to their constant exposure to visual media and technologies. This "visual literacy" as explained by Brumberger, is a highly evolved skill set that enable them to rapidly search for key images and themes, while replacing the need to read large amounts of text, (Brumberger, 2011).

In contrast, other research describes the in class mobile devices as a dark innovation that strikes learning and aptitude. Spangler's (2105) dissertation pointed out frequent misuses of mobile technologies. Spangler's observations declared a culture of classroom distraction layered with disconnect from the faculty lectures and presentations. Students were constantly witnessed obsessing over sports scores, digital shopping adventures, and virtual gamming during class. More interesting than the anti-social aspects and prolific mobile device distractions from core learning was Spangler's discovery of anxiety issues in class from disconnect and power loss to the devices. As an example, students were discovered to seek electronic device connectivity station positions or outlet locations over the ability to see and hear faculty lectures. Participant or informant accolades explained, "We get anxiety over the thought of loosing power or Internet connection during class." One student, a female education major, describe her and peers obsession with getting to classes 15-20 minutes having nothing to do wit the course or education value, but the ability to sit next to a power outlet. "We fear loosing battery power. If you don't get to sit next an outlet, you're screwed if something happens."

Estable's (2013) research found similarity in nature. "Mobile devices can be seen as enablers that facilitated student interactions. They also highlight how the design of mobile technology supported activities that started as in class activities can be used to encourage students to engage with self-directed learning using their own mobile devices," (Estable, 2013). Although Estable's findings are positive in nature, they point out or declare the culture is stricken with mobile technology "enablement."

\section{Concerns and Constraints of BYOD}

Despite good intentions and alignment to the curriculum, there are instances where technology does not become an enabler to the learning process. Factors in university environments such as infrastructure, culture, perception, institutional, and organizational issues can hinder the use or quality of a BYOD environment. In addition, universities are trying to adapt to the constantly changing technologies and as a result are putting additional financial strain to already tight operating budgets, (Petocz, et al, 2013).

It is important that educators understand the needs of students and the environment that the technology will be used. Engagement through technology is not just adding technology to traditional content. Students are relying more on their personal devices for class engagement in the form of discussion boards, class participation. The movement of BYOD to the classroom may be misunderstood by educators who try to incorporate the same traditional approaches on mobile devices (Cochrane, et al., 2014). There is no creativity or innovation to these approaches as educators try to unsuccessfully embrace the mobile trend, (Cochrane, et al, 2014). Additional concerns involve the issue of "Superficial Learning" of students in a mobile learning environment. The idea of having the ability of accessing information quickly and in time may be a detriment to the structure of a learning culture in a class. Students may become dependent on reminders, additional guidance, and constant oversight to continue with readings, assignments, and engagement of course materials, (Petocz, et al, 2014).

Of greater is concern is mobile security measures in higher education platforms. Securing personal devices is crucial. Academic domains are in constant peril to protect information in any situation, but even more so when independent devices are connected to central gates. Inside higher education domains today (2016) are lingering concerns about protocol breaches and network worm intrusion from BYOD devices. Hence, universities are generating BYOD governance policies and seeking guidance for intrusion protection. The prolific use of BYOD innovations on university campuses has raised the need for governance policies, malware detection, and Terms of Service (TOS) agreements in higher education domains. The TOS agreements are designed for protecting its independent servers from intrusion and allowance for device tracking and administrating in the private sector.

With colleges and universities offering Internet services to students on campus through the use of WiFi, security is a new frontier when dealing with BYOD innovations and governance plans. Simply having a good BYOD plan does not guarantee that your business network will be protected. To force counter measures in security issues, universities 
are implementing mandatory Mobile Device Management (MDM) software on all users in TOS agreements. The software, a free download to the user's personal mobile devices, creates a mandatory user acceptance and agreement policy prior to connectivity. MDM allows students and employees to access WiFi, email, and corporate data while keeping their personal data separate. MDM allows a Network Security department control over how these mobile devices access and attempt to change network data as well as the ability to remotely lock and unlock, wipe data, reset a device, require a password, encrypt and decrypt data, enable and disable the camera, screen capture, Bluetooth, GPS, microphone, synchronization, and scan the device inventory (Rhee, Won, Jang, Chae, \& Park, 2013).

\section{FINDINGS}
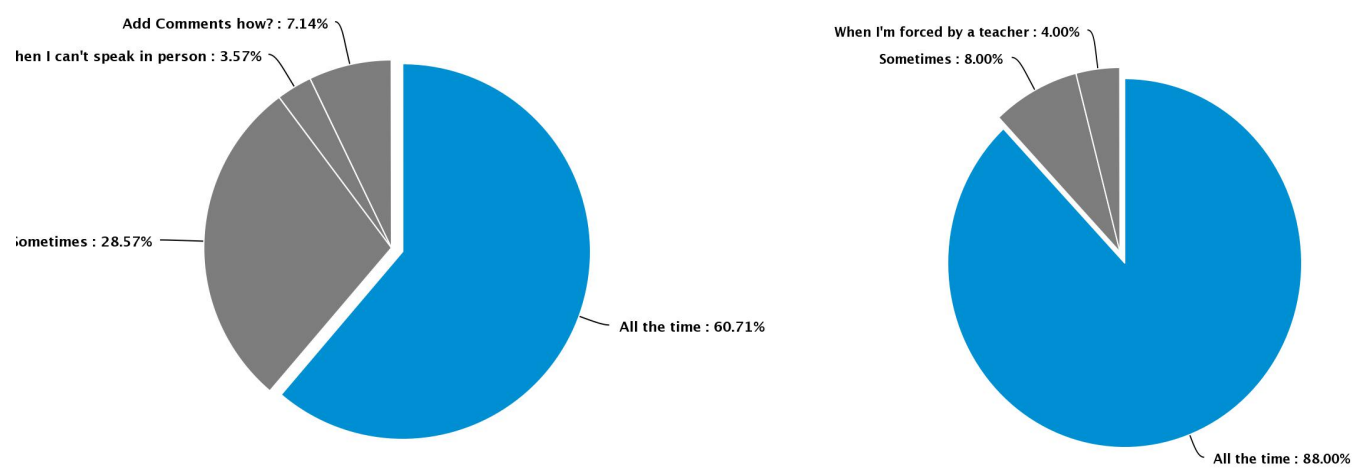

Figure 1. Technology Use to Communicate and Use for Knowledge Seeking

The current data constructs a new pattern forming in digital native sophistication and the scope creep of who is a digital native. More importantly, the scope creep of the digital native community appears to be engulfing or leaving the youth centric matrix. As an example, the data suggests today's (2016) digital native students' parents are technology friendly immigrants and approve of the texting and emailing communication formats. Texting was discovered to be the highest or most acceptable format of communication in the culture with almost a $30 \%$ higher rate than emails and traditional phone conversations. These parents, in all rights, could be considered Tapscott's and Prensky's original digital native dating back to the late 70's in birth record, which would suggest their strong acceptance of innovations and technology with their children. Interestingly point out prior in Spangler's (2015) dissertation was the scope creep factor in the higher education domain. The researcher uncovered through informants that mobile technology proliferation was fostering through low-cost alternatives to the mainstream media's and student center purchasing plans located in college books stores. With this knowledge the technology gap diminishing, data suggests scope creep has entered into the "adult" of parental domains.

This finding might also suggest why the digital native students today are more receptive to communicate outside of their native cultures and with a global audience. Participants stated that race, gender, and nationality have no effect on their communications because in the digital formats there can be no color or race. The ability for a participant to be "anonymous" is readily easier today than in the past. This finding could be considered why respondents remarked a race and gender is diminishing in their cultural communications. Over $50 \%$ of the participants considered their culture's technology use as a progressive format for breaking down the barriers in gender and race communication. 


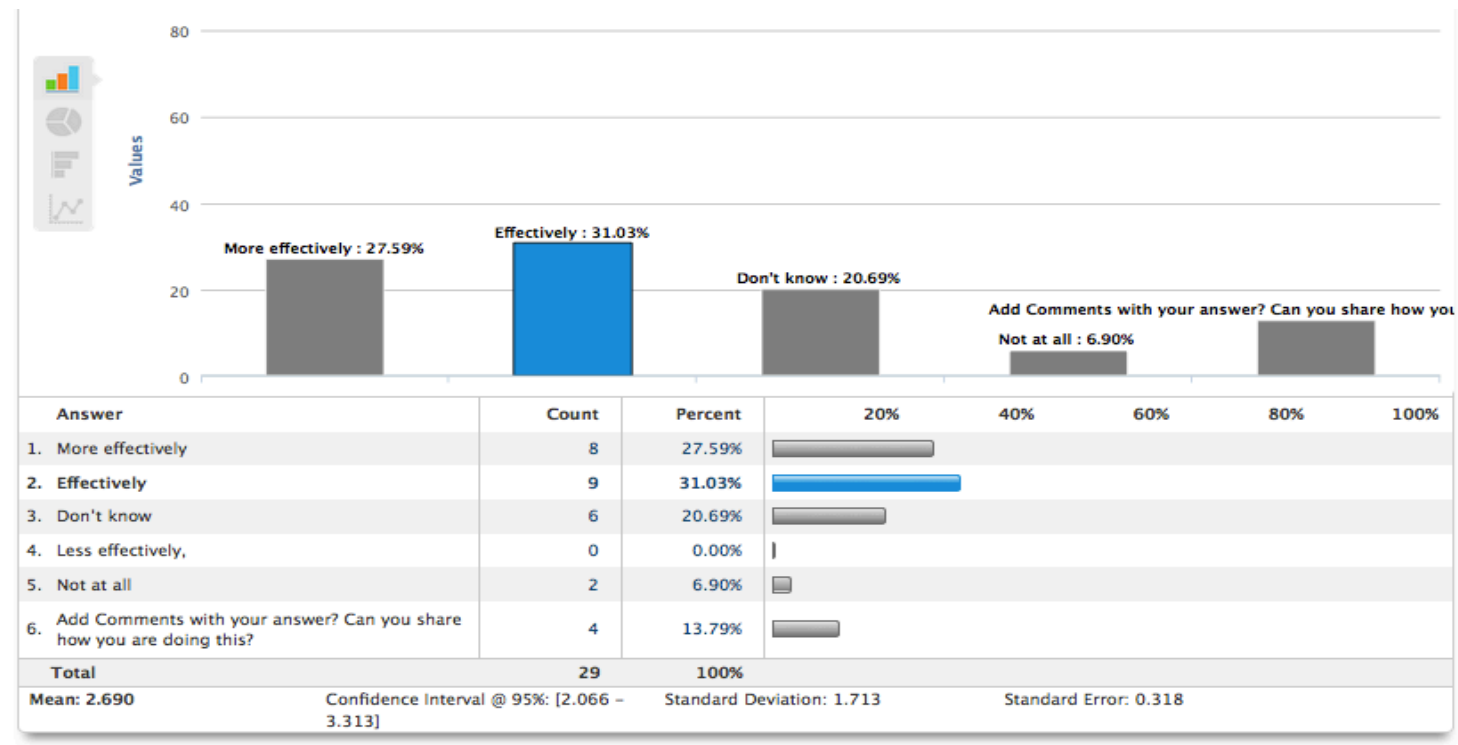

Figure 2. Digital Native's Reflections on Communicating with Difference Races

Participants commented, "I feel that gender lines are being blurred as time goes on. Technology has enabled people to anonymously communicate, and in many cases not know the gender, ethnicity, or religion of the others." Others remarked, "Anonymity removes gender bias in a way that face-to-face interactions cannot." In an agreement one participant elaborated in the discussion describing face-to-face communications as filled with anxieties. Extending on the thought the participant stated technology is diminishing face-to-face anxiety issues in the culture. "Social anxiety may hinder face to face communications, while online; the feeling of 'safety' can help overcome that." Interestingly one participant described texting as a safer form of communication and with a level of projection:

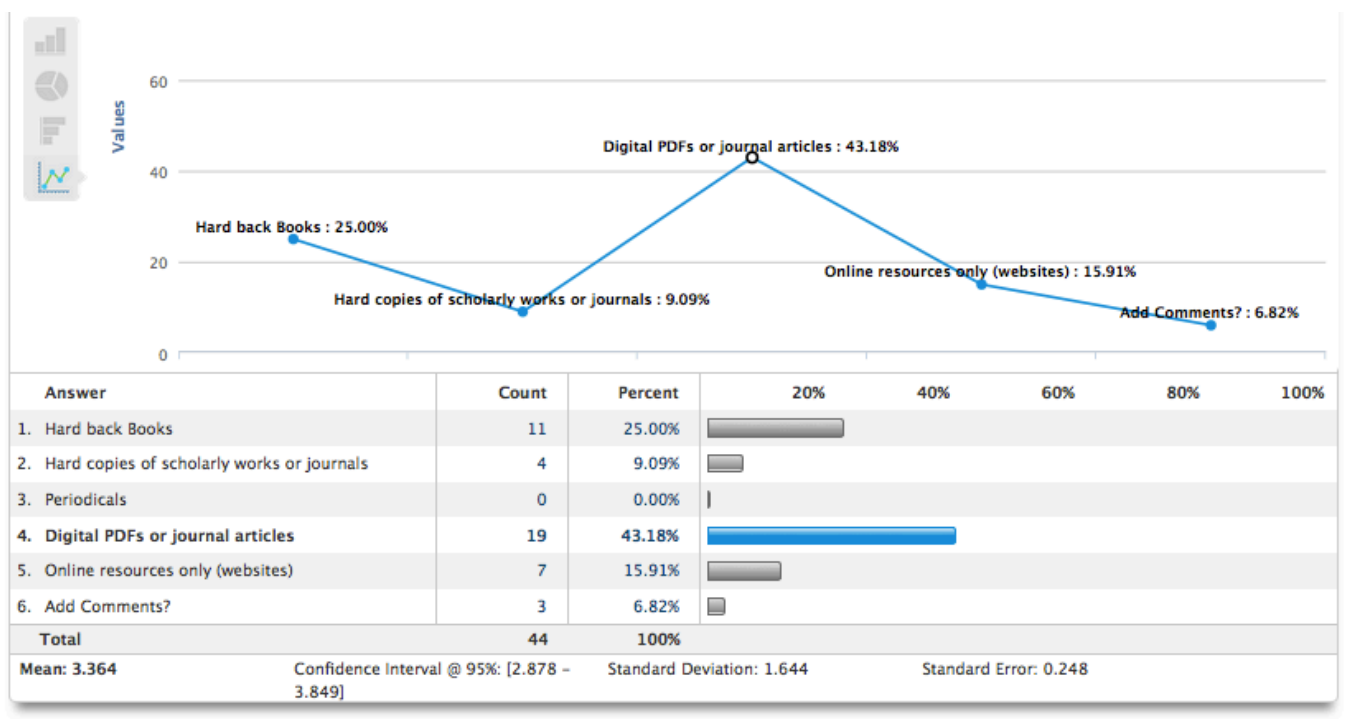

Figure 3. Digital Native's Preference on Media's 
These findings reflect a movement away from physical books and media's in the culture like Rodi et al. (2014) discovered. However, research demonstrates a deeper meaning about why the digital natives are changing habits. Participants' comments reflected the need for "easy" access, "convenience" and "search" specific information. Digital natives are always "plugged in." Their constant connectivity with "Ubiquitous Information Systems" is an entrenched necessity that reduces the need for books and traditional forms of information and communication, (Myers and Sundaram, 2012).

\section{CONCLUSION AND CONTINUING RESEARCH}

In many current and future classrooms, digital natives will engage through the use of their own mobile devices. The classroom will no longer be a prohibitive space for innovation and technology engagement. Educators will and should seek innovative ways to engage students through their mobile devices by incorporating the devices into the curriculum. As a result, teaching and learning will be transformed from traditional approaches and engagement to innovative, unconventional forms of knowledge transfer.

Scholars such as Sugata Mitra's "Hole in the Wall" and "Grandmother in the Cloud" experiments with technology are the starting point to new mobile technology integration in education. With the proliferation of mobile technology increasing and the scope creep in the digital native domain increasing, the term digital native seems to be diminished. Onsets of the scope creep have concurred this factor from the researcher's data and suggest a diminishing technology and educational gap overall. Further research in the domain would lead the scholars' conclusions and suggest (if surveyed in low-income areas across America), a diminished technology gap and literacy gap. As an example, the Commonwealth of Pennsylvania's library grants in rural areas to increase technology and software systems, awareness, and education has fostered a 100,000-user jump in the Ligonier Valley Public Library's log on system analysis yearly.

Interestingly, the researchers" data furthers the original conception of questioning again if the digital natives are dead? With again the onset and proliferation of information technologies (IT) and free IT education on places such as Khan Academy, YouTube, and Ted Talks, the fostered need to scope in the outliers has exceeded scholars' predictions in the literature and educational literature gap areas. This knowledge begs the current researchers to reclassify what is a digital native, and or lump sum all users today into a new scope or matrix. From the suggested or uncovered data, this paper's scholars suggest a renaming and classification system of information Technology (IT) users (Spangler's 2016 Digital Human IT Integration Charting System Model):

- Digital Babies (incoming freshman class users ages 1 to 9);

- Digital Juniors (10 to 15 -years-old, whom have navigated youth in elementary and are in junior high school range with moderate IT knowledge);

- Digital Constructionists (16 to 24-years old, whom have circumnavigated surface IT tech scope and dominated in application knowledge or building); and

- Digital Inhabitants (26 to 65-years-olds that learned naturally or through advanced knowledge seeking interfaces and innovations); and

- Digital Emeritus (65 to ?, whom have learned from others or their own interests IT and innovations for personal prosperity).

The past research and current literature reveals new approaches to engage digital native's culture of technology reliance. With the aid of Spangler's new 2016 Digital Human IT Integration Charting System Model, researchers will be able to readily and easily observer different domains and recalibrate sophistication. This classification system will need further research into descriptions and cultural traits. But nevertheless, Spangler's 2016 Digital Human IT Integration Charting System will accommodate a scholastic and scientific model for breaking down generations and inclusion factors to better understand meanings. It will also create a Roger's adaptive measuring method to observe and understand individual technologies and innovations in each core stage. Then once the scholars have a clearer understand of the matrixes, deeper meanings can be concluded and determined for the advancement of IT knowledge and education. 
The Higher Education environment must be prepared to meet the needs of this cultural shift in learning by embracing the concept of non-traditional teaching through non-traditional strategies. Lastly, the literature points to the need to provide further research in order to clarify as to how digital students respond to a more non-traditional digital learning environment.

\section{REFERENCES}

Bauerlein, M. (2009). The Dumbest Generation: How the Digital Age Stupefies Young Americans and Jeopardizes Our Future (Or, Don't Trust Anyone Under 30). New York, NY: Tarcher.

Bauerlein, M. (2011). The digital divide. New York, NY: Jeremy P. Tarcher

Boyd, D. (2014). It's Complicated: The Social Lives of Networked Teens (1 edition). New Haven: Yale University Press.

Carr, N. (2011). The Shallows: What the Internet Is Doing to Our Brains (Reprint). W. W. Norton \& Company.

Carr, N. (2015). The Glass Cage: How Our Computers Are Changing Us (1 edition). W. W. Norton \& Company.

Goodman, M. (2016). Future Crimes: Inside the Digital Underground and the Battle for Our Connected World (Reprint edition). New York: Anchor.

Hart, M. L., Gray, D. M., Chinburg, S., Saffarian, M., \& Hart, W. (2011). Technical knowledge among undergraduates: Perception versus reality. In Conference Participants, p. 125. Retrieved from http://lupus.northern.edu/academics/Documents/ceib/2011 proceedings.pdf\#page=125

Howe, N., \& Strauss, W. (2007). The Next 20 Years: How Customer and Workforce Attitudes Will Evolve. Harvard Business Review, 85(7/8), 41-52.

Jukes, I., McCain, T. D. E., Crockett, L., \& 21st Century Fluency Project. (2010). Understanding the digital generation: teaching and learning in the new digital landscape. Kelowna, BC; [Thousand Oaks, Calif. ]: 21st Century Fluency Project; Co-published with Corwin, a SAGE Co.

Myers, M.D., Sundaram, D. (2012). Digital natives: Rise of the social Networking Generation. University of Aukland Business Review, 15(1), 28-37.

Palfrey, J., \& Gasser, U. (2010). Born Digital: Understanding the First Generation of Digital Natives (First Trade Paper Edition edition). Basic Books.

Prensky, M. (2001). Digital Natives, Digital Immigrants. On the Horizon (MCB University Press), 9(5), 1-6.

Rhee, K., Won, D., Jang, S., Chae, S., \& Park, S. (2013). Threat modeling of a mobile device management system for secure smart work. Electronic Commerce Research, 13(3), 243-256. doi:10.1007/s10660-013-9121-4

Rodi, A., Spangler, S., Delorenzo, G., \& Kohun, F. (2014). A case study: Are digital natives dead? What are the key factors and perceptions librarian's view of the digital native culture in higher education? Issues in Information Systems, 15(2), 207-213.

Schmidt, E., Cohen, Jared. (13AD). The New Digital Age: Reshaping the Future of People, Nations and Business by Schmidt, Eric, Cohen, Jared (2013) Hardcover. Knopf, 2013. 
Smith, E. E. (2012). The Digital Native Debate in Higher Education: A Comparative Analysis of Recent Literature. Canadian Journal of Learning \& Technology, 38(3), 1-18.

Smith, J., Skrbis, Z., \& Western, M. (2013). Beneath the "Digital Native" myth Understanding young Australians' online time use. Journal of Sociology, 49(1), 97-118. http://doi.org/10.1177/1440783311434856

Spangler, S. (2015). What is the cultural experience of the digital native student today (2015)? (Doctoral dissertation). Pittsburgh, Pa, United States of America: Robert Morris University.

Tapscott, D. (1999). Growing up digital: the rise of the Net generation. New York; London: McGraw-Hill.

Tapscott, D. (2009). Grown up digital: how the net generation is changing your world. New York: McGraw-Hill

Tapscott, D. (2010). Teachers Must let Students Collaborate. In I. Jukes, T. D. E. McCain, \& L. Crockett (Eds.), Understanding the Digital Generation: Teaching and learning in the new digital landscape (pp. 105-112). Kelowna, BC; Canada: SAGE Publications, Inc.

Zukowski, A. A. (2010, March). Navigating the Digital Culture as a DRE: Inch-by-Inch. Momentum, 41(1), 50-52. 